\title{
Effect of Magnetite Nano Particles on p-n-Alkyl Benzoic Acid Mesogens
}

\author{
S. SREEHARI SASTRY ${ }^{1 *}$, S. SALMA BEGUM ${ }^{2}$, T. VINDHYA KUMARI ${ }^{2}$, \\ V. R. K. MURTHY ${ }^{2}$, AND SIE TIONG HA ${ }^{3}$
}
${ }^{1}$ Physics Department, Acharya Nagarjuna University, Nagarjunanagar-522 510,India
${ }^{2}$ Physics Department, Indian Institute of Technology, Chennai-600 036, India
${ }^{3}$ Department of Chemical Science, Universiti Tunku Abdul Rahman, Jalan University, Bandar Barat, Kampar 31900, Perak, Malaysia
sreeharisastry@yahoo.com

Received 23 November 2011; Accepted 15 January 2012

\begin{abstract}
The magnetite $\left(\mathrm{Fe}_{3} \mathrm{O}_{4}\right)$ nanoparticles $(0.5 \mathrm{wt} \%)$ of size less than 20 nm doped in $p$ - $n$-alkyl benzoic acids where $n$ varies from heptyl (7) to nonyl (9) are prepared and the presence of $\mathrm{Fe}^{+3}$ is confirmed through UV-Visible spectrophotometer. Textural and phase transition temperature studies are carried out using polarizing optical microscopy on pure and nano doped $p-n$ alkyl benzoic acids. These results are further confirmed by DSC at a scan rate of $5^{\circ} \mathrm{C} / \mathrm{min}$ and dielectric studies. Dielectric studies are carried out, in which the variation of dielectric constant, loss and the conductivity are analyzed with respect to temperatures and frequencies. Increment of relaxation times for nano doped heptyl and nonyl benzoic acids are observed which implies that the dielectric nature is strengthened for the nano doped mesogens. The preference of nano doped $p$ - $n$-alkyl benzoic acids is discussed.
\end{abstract}

Keywords: magnetite nanoparticles, $p$ - $n$-alkyl benzoic acids, dielectric constant, loss, relaxation time.

\section{Introduction}

Nematic Liquid crystals possess properties favorable to applications related to display, tunable photonics and non-linear optics ${ }^{1}$. Doping has been widely used to enhance the commercial applications of mesogens for dielectric response, operating at low threshold voltages, consuming less power, fast response time, small medium area displays and electro-optical switching characteristics ${ }^{2,3}$. Nano particles doping are very much advantageous for optical, magnetic and biological properties besides catalyses ${ }^{4-6}$. With the high solubility into the nematic mesogens host medium metal oxide nanoparticles are useful 
to develop display materials on their exhibiting frequency modulation response and fast response time ${ }^{7,8}$. Further, the polycrystalline ferrites are very good dielectric materials and have many technological applications ranging from microwave to radio frequencies ${ }^{9}$. Ferrites are also applicable in many magnetic devices due to their low electrical conductivity as compared to that of magnetic materials ${ }^{10,11}$. In this communication, the effects of magnetite $\left(\mathrm{Fe}_{3} \mathrm{O}_{4}\right)$ nanoparticles in the alkyl benzoic acids are studied through textural, phase transitions and dielectric investigations.

\section{Experimental}

$p$ - $n$-alkyl benzoic acids of $n$ varies from heptyl (7) to nonyl (9), and nano magnetite $\left(\mathrm{Fe}_{3} \mathrm{O}_{4}\right)$ of 5-20 nm size are obtained from M/s Frinton Laboratories, Inc. USA and IIT, Chennai respectively. The magnetite $\mathrm{Fe}_{3} \mathrm{O}_{4}$ nanoparticles are introduced in the isotropic state of mesogenic material in the ratio of $0.5 \mathrm{wt} \%$ and subjected to continuously stirring condition for 3 hours. With the UV - Visible spectrophotometer (Jasco make Japan, model No.V670) the presence of $\mathrm{Fe}_{3} \mathrm{O}_{4}$ in the prepared nano doped mesogens is examined. Textural and phase transition temperature measurements are made by the polarizing optical microscope (POM) (Olympus BX50) with attached DP10 camera setup and computer controlled HCS 302 hot stage of Instec, USA. The phase transition studies are also carried out for conformation by using Differential Scanning Calorimeter of TA instruments model DSC Q2000 V24.4 at a scan rate of $5^{\circ} \mathrm{C} / \mathrm{min}$.

Dielectric constant and dielectric loss are measured in the frequency range of $1 \mathrm{~Hz}$ to 1 $\mathrm{MHz}$ at different temperatures on $n \mathrm{BA}$ and $n n \mathrm{BA}$ where $n=7$ to 9 using Newton's $4^{\text {th }}$ Ltd., LCR meter model PSM1700,. Homogeneously aligned ITO coated liquid crystal cells of $5 \mathrm{~mm}$ X $5 \mathrm{~mm}$ X $5 \mu \mathrm{m}$ supplied by M/s Instec. USA are used.

The real part of dielectric permittivity $\left(\varepsilon^{\prime}\right)$ of the sample was obtained from the equation ${ }^{12}$

$$
\varepsilon^{1}=\frac{C p-C o}{C g}+1
$$

Where $C_{p}=$ capacitance of the sample filled LC cell

$C_{o}=$ capacitance of empty LC cell

$C_{g}=$ geometrical capacitance of the LC cell $=\frac{\varepsilon_{o} A}{d}$

$\varepsilon_{o}=$ permittivity of free space

$\mathrm{A}=$ area of ITO coated LC cell

$\mathrm{d}=$ spacing between the cell plates

The loss factor ( $\varepsilon^{11}$ ) given by the equation is $\varepsilon^{11}=\varepsilon^{1} \tan \delta$

The $\tan \delta$ is obtained directly from the data of LCR meter. The accuracy of dielectric constant and loss are estimated to the error of $1 \%$ and $2 \%$ respectively and the temperature accuracy to $\pm 0.1^{\circ} \mathrm{C}$.

\section{Results and Discussion}

\section{Textural and Phase Transition Studies}

The textural observations of pure $p$ - $n$-alkyl benzoic acids $(n \mathrm{BA})$ and magnetite nanodoped alkyl benzoic acid mesogens (nnBA) made through POM have shown enantiotropic 
nematic phase and shown in Figure 1. However, the data presented in Table 1 indicated that the phase transition temperatures (I-N and $\mathrm{N}-\mathrm{Cr}$ ) are lower for nanodoped as compared to the pure samples. The data of the phase transition temperatures measured from both POM and DSC and of the dielectric studies are in good agreement.

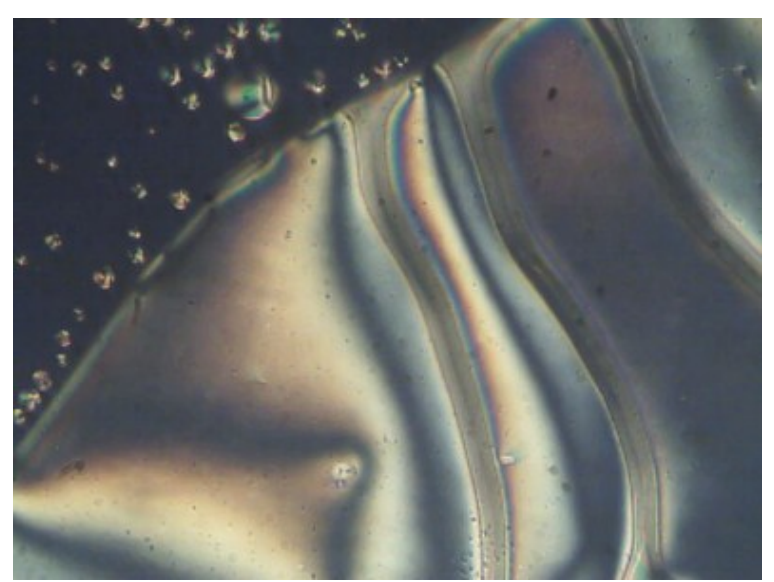

Figure 1. Threaded nematic texture.

Table 1. Phase transition temperatures in ${ }^{0} \mathrm{C}$.

\begin{tabular}{ccc}
\hline Compound & $\mathbf{I}-\mathbf{N}$ & $\mathbf{N}-\mathbf{C r}$ \\
\hline 7BA (n7BA) POM & $121.7(109.7)$ & $102.5(87.5)$ \\
DSC & $117.5(112.1)$ & $102.7(89.5)$ \\
Dielectric Study & $115(110.9)$ & $102.8(91.4)$ \\
8BA (n8BA) POM & $110.3(91.7)$ & $98.9(72.4)$ \\
DSC & $109.6(95.8)$ & $99.1(88.4)$ \\
Dielectric Study & $109(97.5)$ & $97(70.5)$ \\
9BA (n9A) POM & $115.8(100.8)$ & $90.1(85.9)$ \\
DSC & $111.5(103.8)$ & $90.9(85.8)$ \\
Dielectric Study & $116.2(102.5)$ & $91.3(86.5)$ \\
\hline
\end{tabular}

Where I - Isotropic , N - Nematic , $\mathrm{Cr}$ - Crystalline and ( ) values indicates Transition

temperatures of nano doped $p$ - $n$-alkyl benzoic acids.

\section{$U V$ - Visible Spectral Studies}

The UV-Visible spectra of pure and nano doped samples of 7BA mesogens are shown in the Figure 2 as a representative case. It is observed that the spectrum of pure $n \mathrm{BA}$ doesn't exhibit any absorption peaks in the wavelength range of $200 \mathrm{~nm}-2000 \mathrm{~nm}$. However, the spectrum of n7BA (nanodoped 7BA) shows three significant peaks at $418 \mathrm{~nm}, 681 \mathrm{~nm}$ and $821 \mathrm{~nm}$, which are the characteristic peaks of $\mathrm{Fe}^{3+}$ ion $^{13,14}$. So, the UV-Visible spectral study confirms the presence of $\mathrm{Fe}_{3} \mathrm{O}_{4}$ nanoparticles in the prepared nanodoped mesogens. 


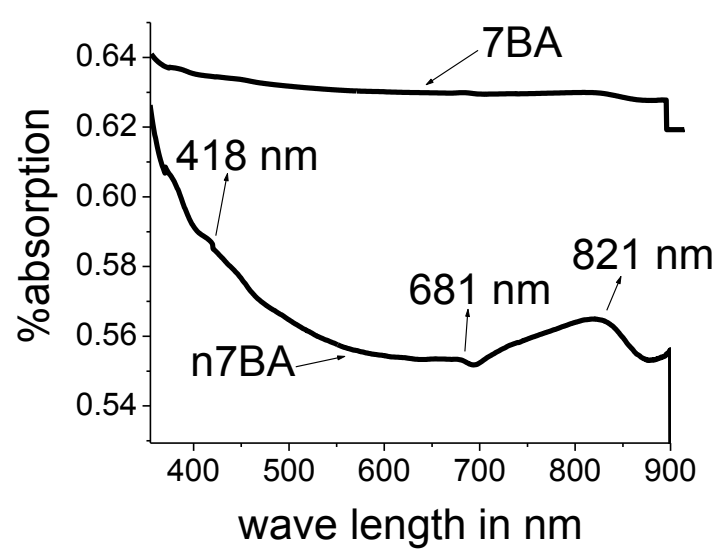

Figure 2. UV-Visible spectra of 7BA and n7BA.

\section{Dielectric Studies}

Eventhough the homologous series of $n \mathrm{BA}$ from $\mathrm{n}=7$ to 9 for pure and nanodoped samples are studied, the dielectric spectra of the 8BA and n8BA mesogens are shown in Figure 3 to represent as a typical case here. The dielectric permittivity $\left(\varepsilon^{1}\right)$ and loss $\left(\varepsilon^{11}\right)$ as a function of frequency at different temperatures of 8BA is shown in Figures 3(a) and 3(b); and for n8BA in Figures 3(c) and 3(d). The measured $\left(\varepsilon^{\prime}\right)$ is the perpendicular component of permittivity as the applied field from LCR meter is perpendicular to the initial orientation of molecules in liquid crystal cell and this $\varepsilon^{\prime}$ decreases gradually with increasing frequency and increases with increasing temperature. The higher value of $\varepsilon^{\prime}$ for increasing temperature indicates the homogeneous alignment of liquid crystal (LC) molecules within the LC cell. The relaxation frequency which is the maximum value of $\varepsilon^{\prime \prime}$ on the curve is almost same throughout the nematic phase at about $100 \mathrm{~Hz}^{15}$.

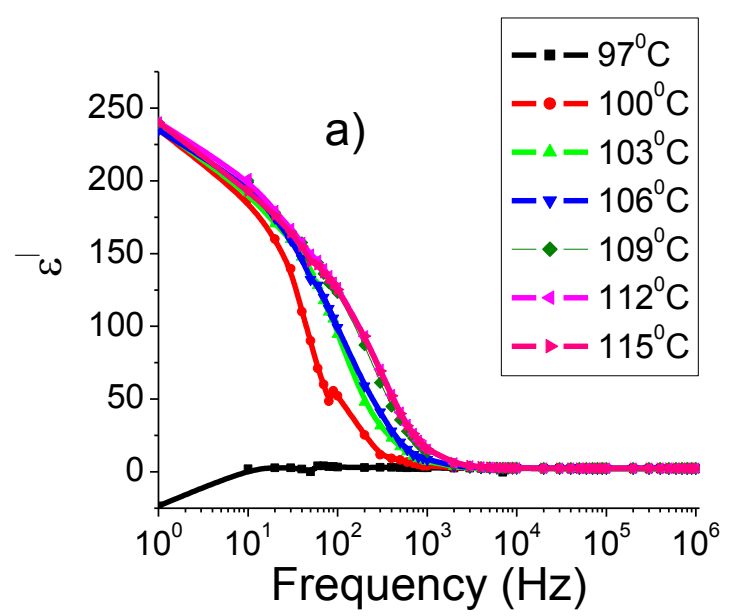

Figure 3(a). Frequency dependence of Dielectric constant $\left(\varepsilon^{\prime}\right)$ of 8BA. 


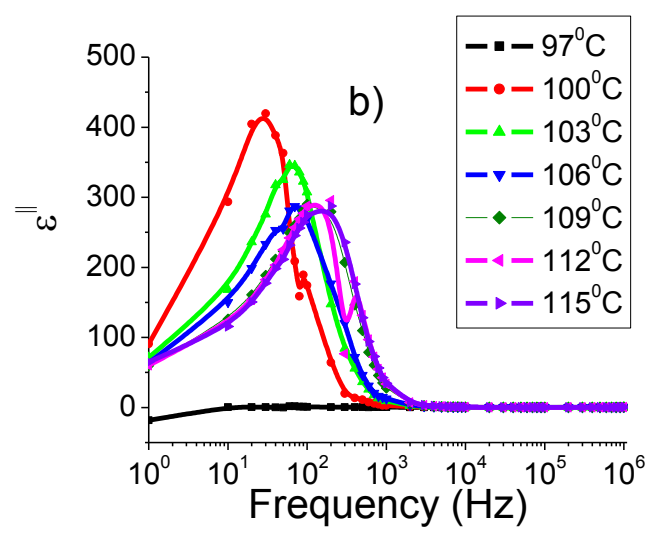

Figure 3(b). Frequency dependence of Dielectric loss $\left(\varepsilon^{\prime \prime}\right)$ of 8BA.

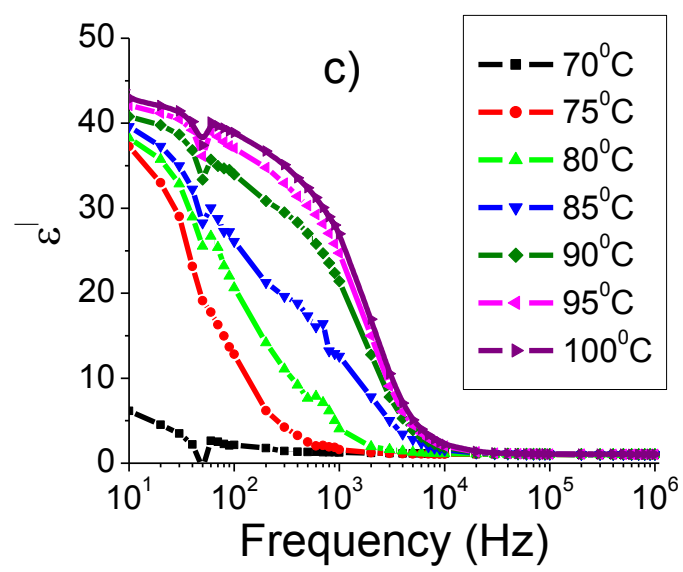

Figure 3(c). Dielectric constant $\left(\varepsilon^{\prime}\right)$ Vs frequency of n8BA.

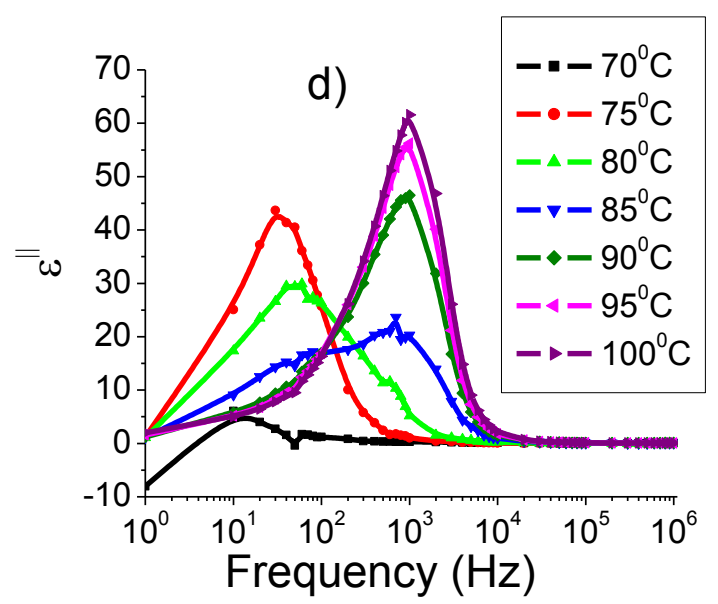

Figure 3(d). Dielectric loss $\left(\varepsilon^{\prime \prime}\right)$ Vs frequency of n8BA. 
The decrease in permittivity with frequency can be explained on the basis of Koop's theory ${ }^{16}$, which considers the dielectric structure as an inhomogeneous medium of two layers of the Maxwell-Wagner type ${ }^{17}$. In this model, the dielectric structure is assumed to be consisting of well conducting grains which are separated by poorly conducting grain boundaries. At lower frequencies the grain boundaries are more effective for conductivity and permittivity than grains ${ }^{18}$. Therefore, permittivity is high at lower frequencies and decreasing as frequency increases. The decrease in permittivity takes place when the jumping frequency of electric charge carriers cannot follow the alternation of the applied a.c. electric field beyond a certain critical frequency.

The comparison of pure mesogens with their respective nanodoped samples are shown in Figure 4 as a representative case. It is observed that the variation of dielectric permittivity against frequency shows almost similar behavior of the pure and nanodoped mesogens. However, the dielectric strength of n8BA is comparatively low and the values of $\varepsilon^{\prime}$ are higher for $\mathrm{n} 7 \mathrm{BA}$ and $\mathrm{n} 9 \mathrm{BA}$ relative to their respective pure mesogens. This nature may be attributed to the dielectric strengths of n7BA and n9BA are more than that of pure 7BA and 9BA.
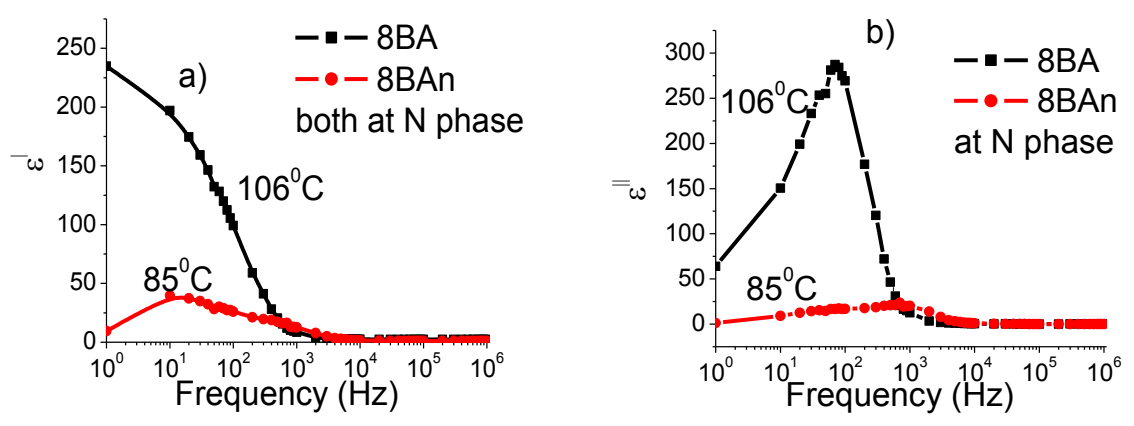

Figure 4. Frequency dependence of (a) $\varepsilon^{\prime}$ and (b) $\varepsilon^{\prime \prime}$.

\section{Evaluation of transition temperatures from the dielectric studies}

The variation of $\varepsilon^{\prime}$ and $\varepsilon^{\prime \prime}$ with temperatures for samples of 8BA and n8BA are shown in Figure 5 as a typical case. From the figures, it is observed that the values of $\varepsilon^{\prime}$ remain almost constant up to solid phase and vary slightly when the transition from solid to nematic has been reached and the value changes sharply when isotropic state has reached.

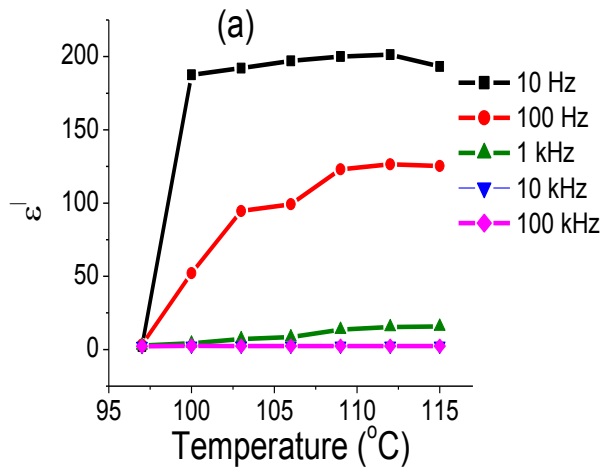

Figure5(a). $\varepsilon^{\prime}$ Vs Temperature for 8BA.

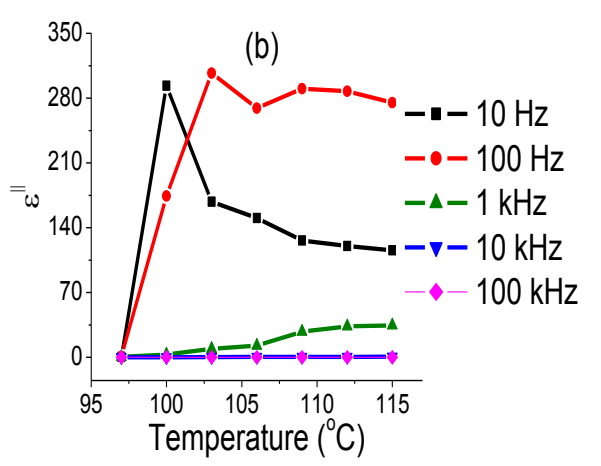

Figure5(b). $\varepsilon^{\prime \prime}$ Vs Temperature for 8BA. 


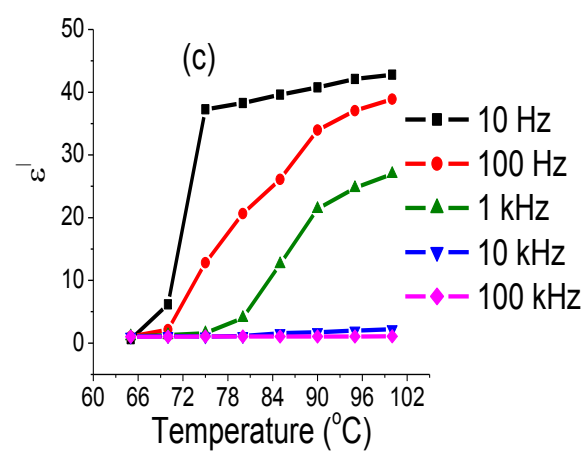

Figure5(c). $\varepsilon^{\prime}$ Vs Temperature for n8BA.

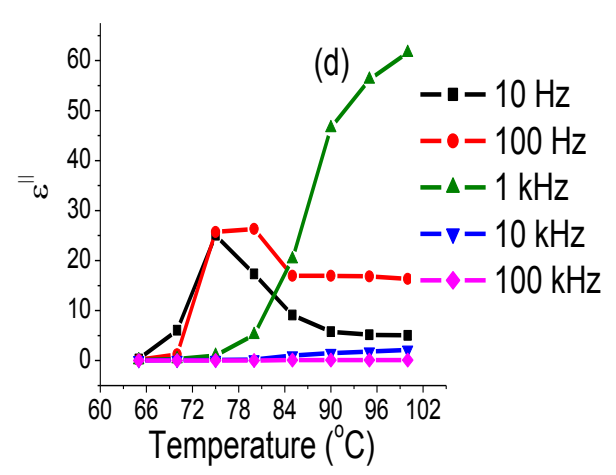

Figure5(d). $\varepsilon^{\prime \prime}$ Vs Temperature for n8BA.

So, the transition temperatures mentioned in Table 1 are $97^{\circ} \mathrm{C}(\mathrm{Cr} \rightarrow \mathrm{N})$ and $109^{\circ} \mathrm{C}(\mathrm{N} \rightarrow \mathrm{I})$ for $8 \mathrm{BA}$ and $70^{\circ} \mathrm{C}(\mathrm{Cr} \rightarrow \mathrm{N})$; and $90^{\circ} \mathrm{C}(\mathrm{N} \rightarrow \mathrm{I})$ for $8 \mathrm{BAn}$. Hence, we can confirm the transition temperatures of prepared nanodoped mesogens through dielectric dispersion curves. Similar type of behavior has also been observed for the curves of $\varepsilon^{\prime \prime}$ Vs temperature at different frequencies.

As a part of dielectric study through N4L LCR meter, the resistance values of samples were also measured at different frequencies. It is observed the resistance of nanodoped 7BA and 9BA is more than that of pure 7BA and 9BA. That means, the conductivity is less in n7BA than in pure 7BA. This behavior indirectly strengthens the behavior of $\varepsilon^{\prime}$ of the both samples and it's converse the case of n8BA which is shown in Figure 6.

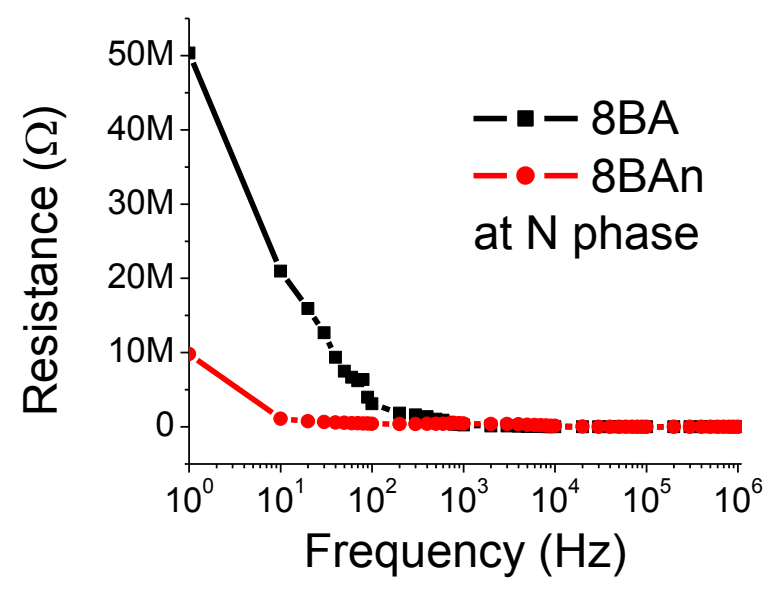

Figure 6. Frequency Vs Resistance.

However, in the case of $8 \mathrm{BA}$ and n8BA samples, the dielectric permittivity of n8BA is considerably decreased compared to $8 \mathrm{BA}$ and the peak in the curves $\varepsilon^{\prime \prime}$ shifts towards higher frequency for n8BA. This type of behavior of n7BA and n8BA is due to the difference in alkyl chain length and it is expected to show even-odd effect in the homologous series ${ }^{19,20}$. 
Variation of Dielectric loss with respect to Dielectric constant

The variations between $\varepsilon^{\prime \prime}$ and $\varepsilon^{\prime}$ plotted at the nematic temperatures for both pure and nanodoped samples are shown in Figures 7(a) to (d). From these Figures, the relaxation frequency $\left(f_{r}\right)$ corresponding to the peak value of the curve is determined and then, the relaxation time is calculated with the equation $\tau=1 / \omega$, where $\omega=2 \pi \mathrm{f}_{\mathrm{r}}^{20}$.

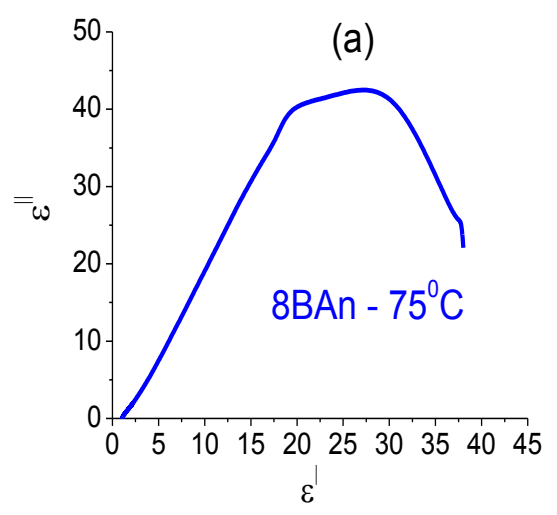

Figure7(a). $\varepsilon^{\prime} \operatorname{Vs} \varepsilon^{\prime \prime}$.

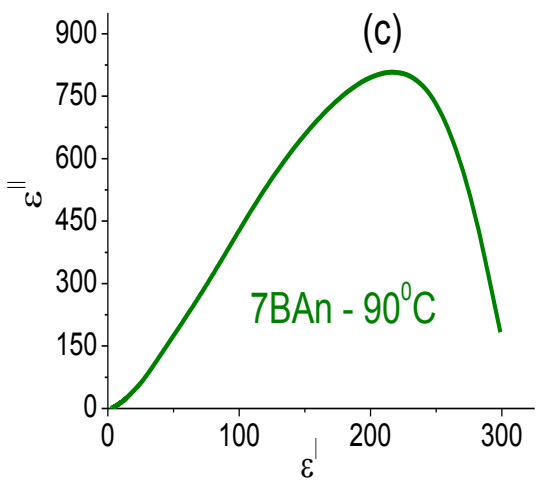

Figure7(c). $\varepsilon^{\prime} \mathrm{Vs} \varepsilon^{\prime \prime}$

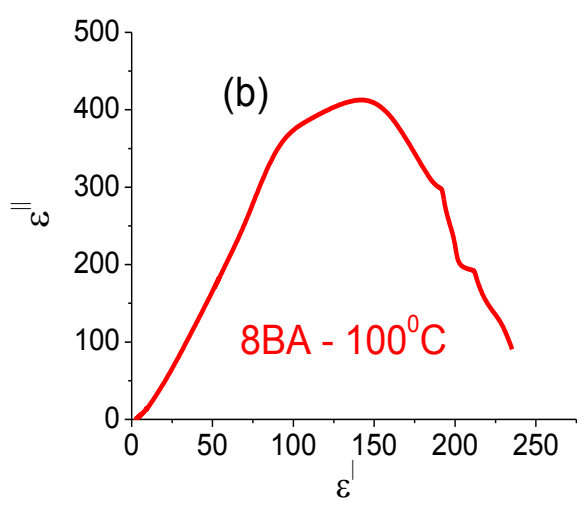

Figure7(b). $\varepsilon^{\prime} \operatorname{Vs} \varepsilon^{\prime \prime}$.

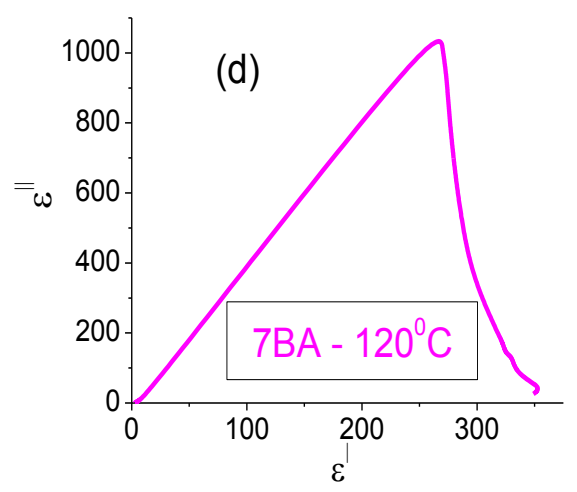

Figure7(d). $\varepsilon^{\prime} \operatorname{Vs} \varepsilon^{\prime \prime}$.

The relaxation times and relaxation frequencies at their nematic phase are tabulated in Table 2. The relaxation time for nanodoped samples has increased, which is due to the rotation of rigid dipoles that is a measure of frictional resistance to the rotation (rotational viscosity $^{21}$. For n8BA, the decrease in relaxation time was also identified, which supports the free rotation of molecules in the presence of magnetite nanoparticles. Also, the data inferred that the molecules of higher homologues will relax at lower frequencies in nanodoped samples. 
Table 2. Relaxation Frequencies and Relaxation times.

\begin{tabular}{cccc}
\hline Compound & Temperature $\left({ }^{\circ} \mathrm{C}\right)$ & Frequency $\left(\mathrm{F}_{\mathrm{r}} \mathrm{Hz}\right)$ & Relaxation time $(\tau \mathrm{mSec})$ \\
\hline 7BA & $110-120$ & 1000 & 0.1591 \\
n7BA & $95-100$ & 50 & 3.1847 \\
8BA & 100 & 30 & 5.3051 \\
n8BA & 75 & 40 & 3.9808 \\
9BA & 110 & 300 & 0.5307 \\
n9BA & 100 & 200 & 0.796 \\
\hline
\end{tabular}

The dispersion of magnetite $\left(\mathrm{Fe}_{3} \mathrm{O}_{4}\right)$ nanoparticles in the liquid crystals at their isotropic state formed into ferrofliuds ${ }^{21}$. The doping of nano in the mesogen made them to use in technological applications for improving performance of audio speakers and as a liquid crystal template.

The variation in the values of $\varepsilon^{\prime}$ and $\varepsilon^{\prime \prime}$ due to addition of magnetite nanoparticles can be explained by considering the contribution of dipole moment or dipoles orientation of $\mathrm{Fe}_{3} \mathrm{O}_{4}$ molecules on the pretilt angle of LC molecules resulting in the restriction on the freedom of movement. Thus, the dipole moment of $\mathrm{Fe}_{3} \mathrm{O}_{4}$ molecule contributes significantly to the actual value of $\varepsilon^{\prime}$ and $\varepsilon^{\prime \prime}$ and also to the relaxation frequency value ${ }^{22}$. In our observations, value of $\varepsilon^{\prime}$ increases for n7BA, n9BA and decreases for n8BA, and the expected polarization is orientational (or dipolar) due to the rotational displacement of dipoles presented in $n \mathrm{BA}$ and $\mathrm{Fe}_{3} \mathrm{O}_{4}$ when placed in an electric field ${ }^{23}$. This orientational polarization is more intense in nanodoped mesogens as the doped nanoparticles are ferrite type and possess free rotational dipoles ${ }^{24}$.

The presence of magnetite nanoparticles causes changes in the parameters of near-electrode relaxation process. As seen from the Table 2, the doping of magnetite nanoparticles into mesogen results in increasing the relaxation time and thickness of near-electrode area. This is because of the increase in adhesion energy of LC molecules to substrate with the presence of magnetite nanoparticles ${ }^{22}$.

\section{Conclusion}

The successful doping of magnetite $\left(\mathrm{Fe}_{3} \mathrm{O}_{4}\right)$ nanoparticles in the interstices of host LC material is confirmed through UV-Visible spectral studies. The presence of magnetite nanoparticles at the interstices of $n \mathrm{BA}$ LC molecular system causes the LC molecules to bend, owing to larger rotation eccentricity and thus reducing the transition temperatures which is observed through POM and DSC studies. The dielectric constant variation with frequency shows the nature of materials that follow Koop's theory in which the dielectric structure is having more conductivity at low frequencies. The changes in the values of $\varepsilon^{\prime}$, $\varepsilon^{\prime \prime}$ and relaxation times for $n n \mathrm{BA}$ samples are due to the contribution of dipole moment of $\mathrm{Fe}_{3} \mathrm{O}_{4}$ nanoparticles and the increase in the adhesion energy of LC molecules to the substrate with the presence of these nanoparticles, in spite of their concentration is very low $(0.5 \mathrm{wt} \%$ of host LC). 


\section{Acknowledgments}

One of the authors (SSB) is grateful to University Grants Commission for providing research fellowship for meritorious students under Special Assistance Program to the department of Physics, Acharya Nagarjuna University. The authors gratefully acknowledge the Project No.: ERIP/ER/0703688/M/01/1134, dated 31-03-2010 of Defense Research Development Organization, New Delhi. The authors are thankful to Prof. S. Ram Prabhu, Indian Institute Technology, Chennai for providing the nano $\mathrm{Fe}_{3} \mathrm{O}_{4}$ compound.

\section{References}

1. Heng M, Xinpu F, Hiroyuki O and Hiroyoshi O Liq Cryst, 2009, 36, 835-838.

2. Rajiv M, Sat Prakash Y, Abhishek Kumar S, Abhishek Kumar M, Kamal Kumar P, Prashant K S and Avinash Chand P Jpn J Appl Phys, 2009, 48, 101501-1-6.

3. Tianyi Z, Chengmei Z and Jun X. Jpn J Appl Phys, 2009, 48, 055002-1-6.

4. Kohei F, Akiyoshi C, Kohei K, Toru S, Yuji H, Masaru M, Kanenaga F, Junji H and Mamoru J Appl Phys, 1994, 75, 3075-3080.

5. $\quad$ Ping L, Jian D and Naoki T Langmuir, 1999, 15, 7980-7992.

6. $\quad$ Link S, Wang ZL and El-Sayed M A. J Phys Chem B, 1999, 103, 3529-3533.

7. Gavrilko T, Kovalchuk O, Nazarenko V, Puchkovska G, Shymanovska V, Hauser A and Kresse Ukr J Phys, 2004, 49, 1167-1173.

8. David Appl Phys Lett, 2005, 86, 033507-1-6.

9. Kharabe RG, Devan RS, Kanamadi CM and Chougule Smart Mater Struct, 2006, 15, N36-N39.

10. Shalendra K, Alimuddin, Ravi K, Thakur P, Chae,K, Basavaraj A and Choi WK $J$ Phys: Condens Matter, 2007, 19, 476210.

11. Bhargava SC and Zeman N Phys Rev B, 1980, 21, 1717-1725.

12. Rajeev M, Srivastava AK, Chand PB, Misra AK, Prajapati AK and Varia MC Res $J$ Appl Sci Eng Tech, 2009, 1, 66-76.

13. Mishra AK, Das D Mat Sci Engg B, 2010, 171, 5-10.

14. Wang YS, John TP and OBrien P J Phys Chem B, 2008, 110, 4099-4104.

15. Kumar A, Silotia P and Biradar AM J Appl Phys, 2010, 108, 1-7.

16. Koops C G Phys. Rev. 1951, 83, 121-124.

17. Wagner K W Trans A I E E, 1922, XLI, 288-299.

18. Shaikh AK, Bellad SS and Chougule BK J Magn Magn Mater, 1999, 195, 384-390.

19. Deepa P, Prashant M, Misra AK, Rajiv M and Shukla JP Res J Phys, 2007, 1, 10-18.

20. Laogun AA Phys Med Biol, 1986, 31, 893-900

21. Partricia B, Nicholas B A, Katie J B, Dean J C, Arthur B E and George C L J Chem Educ 1999, 76, 943-948

22. Peter K, Milan T, Ivana P, Martina K, Alena J, Natalia T, Julius S, Ctibor M and Juraj B J Magn Magn Mater Proc 10th Intl Conf Magn Fluids, 2005, 289, 97-100.

23. Kambale RC, Shaikh PA, Bhosale CH, Rajpure KY and Kolekar YD Smart Mater Struct, 2009, 18:085014, 1-6.

24. Rabinkin LT and Novikova ZI Ferrites. Minsk Acad Nauk, USSR, 1996, p 146. 


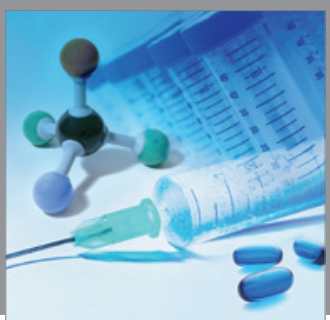

International Journal of

Medicinal Chemistry

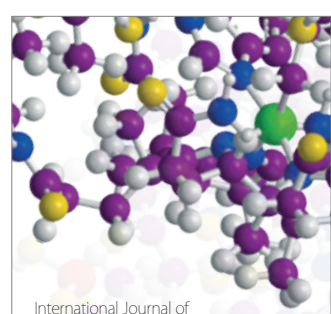

Carbohydrate Chemistry

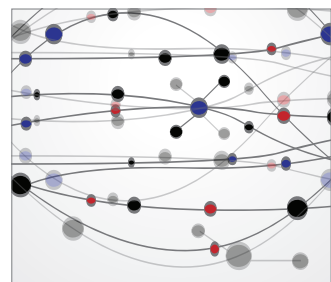

The Scientific World Journal
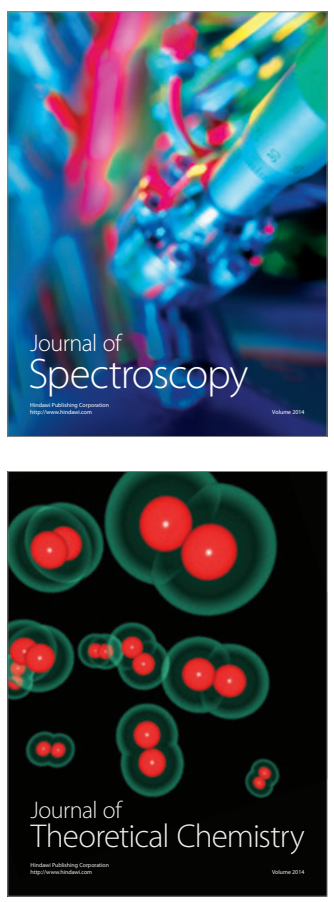
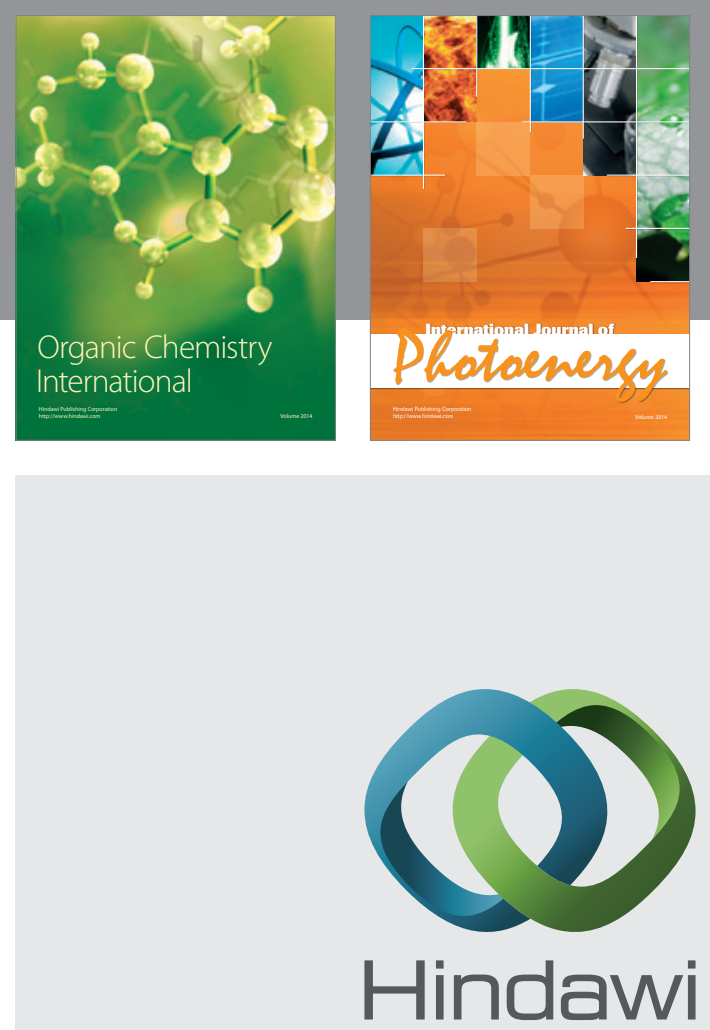

Submit your manuscripts at

http://www.hindawi.com
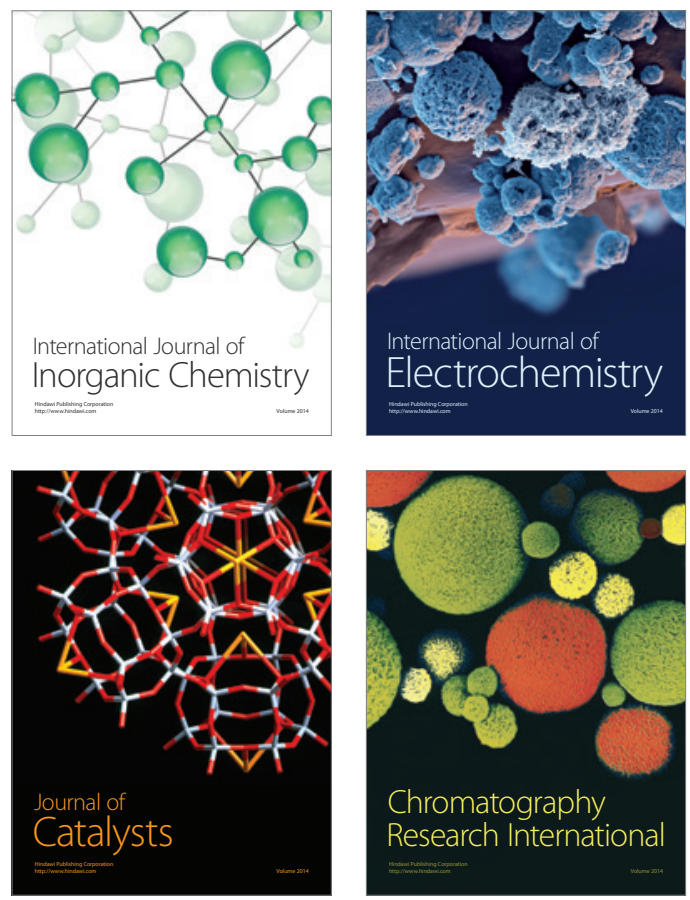
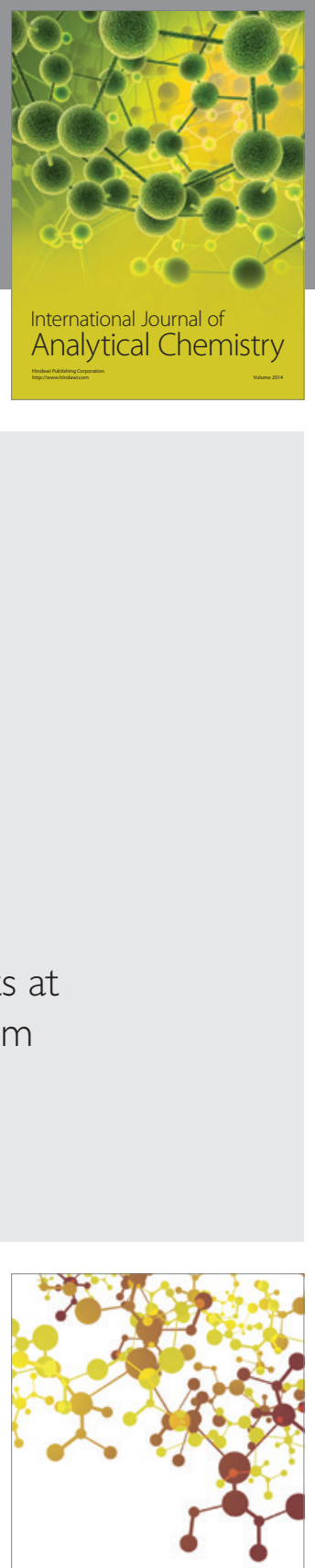

Journal of

Applied Chemistry
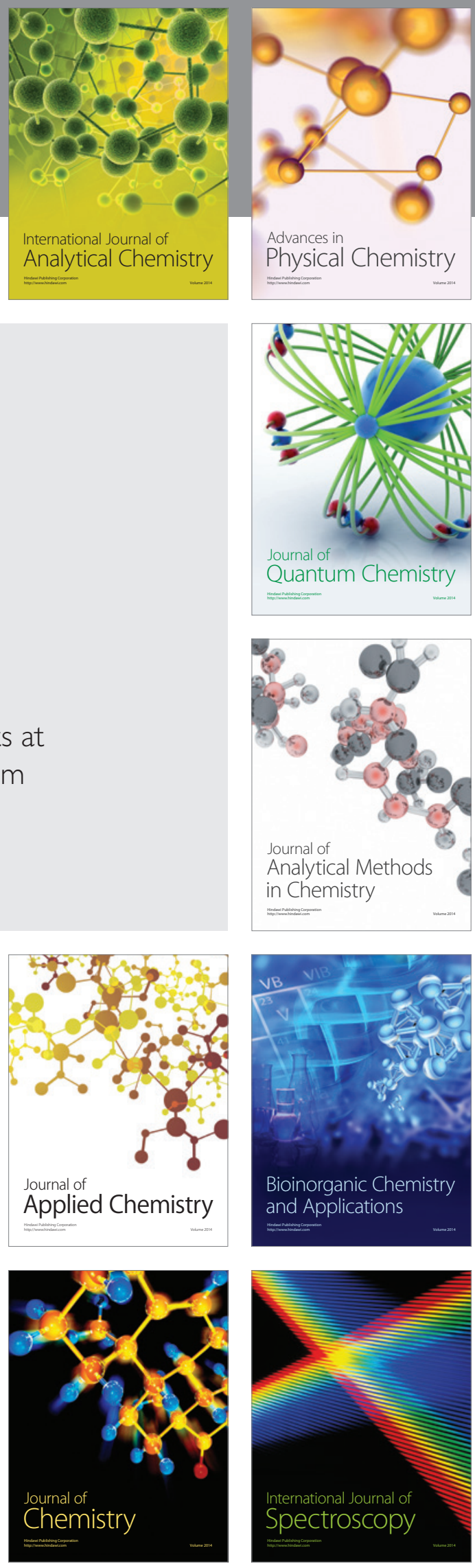